\title{
A INFLUÊNCIA DAS POLÍTICAS DE EDUCAÇÃO E SAÚDE NOS CURRÍCULOS DOS CURSOS DE EDUCAÇÃO PROFISSIONAL TÉCNICA DE NÍVEL MÉDIO EM ENFERMAGEM
}

\author{
THE INFLUENCE OF THE EDUCATION AND HEALTH POLICIES IN THE CURRICULA OF THE \\ MID-LEVEL TECHNICAL PROFESSIONAL EDUCATION IN NURSING
}

Suze Rosa Sant' Anna ${ }^{1}$

Lílian Dias Ennes ${ }^{2}$

Luiza Helena da Silva Soares ${ }^{3}$

Sandra Regina de Oliveira ${ }^{4}$

Leonardo da Silva Sant ${ }^{\prime}$ Anna ${ }^{5}$

Resumo O presente artigo tem por objetivo descrever as principais mudanças ocorridas na educação profissional técnica de nível médio, nos últimos dez anos. Enfatiza-se no trabalho o processo de reorganização curricular dos cursos de educação profissional técnica de nível médio em enfermagem, frente aos princípios, diretrizes e conceitos estabelecidos pelas políticas instituídas no campo da educação em saúde, cujo objetivo é formar trabalhadores de saúde com competência profissional necessária para rever e redirecionar a realidade de saúde do país.

Palavras-chave educação profissional técnica de nível médio; enfermagem, currículo.
Abstract The purpose of this article is to describe the main changes that have taken place in mid-level technical professional education in the past ten years. The article emphasizes the curricular reorganization process that has been undertaken in the mid-level technical professional education for nursing in order to deal with the principles, guidelines, and concepts set forth by the policies that have been instituted in the education and health fields, the goal of which is to qualify health workers who have the required professional competency to review and redirect the reality of health in Brazil.

Keywords mid-level technical professional education; nursing; curriculum. 


\section{A Lei de Diretrizes e Bases e sua influência no processo de reforma da educação profissional técnica de nível médio em enfermagem}

A educação profissional técnica sofreu diversas mudanças nestes últimos vinte anos, inclusive na nomenclatura, que foi alterada de 'cursos técnicos profissionalizantes' para 'educação profissional técnica de nível médio', conforme artigo $3^{\circ}$ da resolução dos Conselho Nacional de Educação e do Conselho de Educação Básica (CNE/CEB) nº 01/2005.

Vários foram os fatores que delinearam as mudanças no cenário da educação profissional (EP), dentre eles, as transformações profundas nos planos econômico, político, social, as quais tiveram como pano de fundo a crise do capitalismo mundial produzida na década de 1970.

Segundo Ferreti e Silva Júnior (2000), o estágio de acumulação capitalista que se iniciou nos chamados 'anos dourados', datados entre a Segunda Guerra até os anos de 1970, entrou em crise. Dentre as justificativas expostas para esta crise, destaca-se a queda de produtividade do modelo de desenvolvimento fordista de acúmulo de capital. O modelo fordista, caracterizado pelo grau de mecanização e profunda divisão técnica do trabalho, tornou-se obsoleto com os novos processos de trabalho que passaram a ser organizados por um outro padrão tecnológico, que utiliza a ciência, a tecnologia e a informação como suas forças produtivas centrais e como fonte de concorrência intercapitalista em um mercado globalizado.

Esta nova ordem econômica mundial, ou seja, esta outra etapa do capitalismo ou novo estágio de acumulação capitalista, necessita de uma nova organização dos processos de trabalho. Para Ferreti e Silva Junior:

“o trabalho passa a ser organizado tendo como objetivo a flexibilidade, ou seja, a possibilidade de alteração, sem comprometimentos, da velocidade de produção, da qualidade do processo e do produto; do próprio projeto; do processo de produção a partir da alteração feita no projeto, e da execução das duas últimas funções simultaneamente. (...) Essas características conferem à nova base produtiva a capacidade de mudanças rápidas, e sem prejuízos, dos produtos, dos processos, tornando a nova empresa muito competitiva se domina esse novo padrão tecnológico" (Ferreti e Silva Junior, 2000, p. 56).

Estes processos de trabalho, organizados pela nova ordem econômica mundial, influenciaram inúmeras reformas em nível planetário, inclusive no campo da educação, que ocupa um espaço institucionalizado central na formação de sujeitos-trabalhadores. No Brasil, este contexto de transformação das relações entre educação, trabalho, ciência e tecnologia culminou em reformas no campo da educação, que teve seu ápice na promulgação da Lei de Diretrizes e Bases (LDB) nº 9394, de 20 de dezembro de 1996. 
A LDB, de fato, gerou consideráveis mudanças tanto da educação básica quanto na educação superior, com destaque especial para a educação profissional, que, de forma inédita, foi objeto de um capítulo da lei. Merece destaque, também, que, com a LDB, tanto a educação básica, cuja etapa final é o ensino médio, como a educação profissional passaram a ter por finalidade a preparação do educando para o trabalho, de modo a capacitá-lo a se adaptar com flexibilidade a novas condições de ocupação ou aperfeiçoamento.

Cabe acrescentar que a educação profissional, segundo o artigo 39 da LDB e o decreto $\mathrm{n}^{0} 5.451$, de 23 de julho de 2004, é estruturada por meio de cursos e programas de formação inicial e continuada, que incluem a capacitação, o aperfeiçoamento, a especialização e a atualização, ofertados em todos os níveis de escolaridade pela educação profissional técnica de nível médio, que será desenvolvida de forma articulada com o ensino médio e, também, pela educação profissional tecnológica de graduação e de pósgraduação, que é oferecida após conclusão da educação básica.

Com base nesse decreto, percebe-se que a educação profissional, cujo objetivo é desenvolver aptidões para a vida produtiva e social de jovens, adultos e trabalhadores em geral, necessita de uma educação básica de qualidade como condição indispensável para o êxito num mundo pautado pela competição, inovação tecnológica e crescentes exigências de qualidade, produtividade e conhecimento.

Nesta ótica, percebe-se que o enfoque dado pela LDB, principalmente no que tange à EP técnica de nível médio, supera o entendimento tradicional da EP centrado no modelo fordista de mão-de-obra, que prepara o aluno-trabalhador para a execução de um determinado conjunto de tarefas, para um outro modelo que requer que o cidadão tenha, além do domínio operacional de um determinado fazer, a compreensão global do processo produtivo, com a apreensão do saber tecnológico, a valorização da cultura do trabalho e a mobilização dos valores necessários à tomada de decisões.

Esta nova concepção de EP agrega o conceito de competência como elemento orientador de currículos dos cursos profissionalizantes. Conforme é descrito nos Referenciais Curriculares Nacionais para a Educação Profissional de Nível Técnico, elaborado pelo MEC em 2000, os currículos: passam a ser encarados como conjuntos integrados e articulados de situaçõesmeio e organizados para promover aprendizagens profissionais significativas. Portanto, não devem mais estar centrados em conteúdos, mas sim em competência, conceituada como uma combinação integrada de conhecimentos (o 'saber'), habilidades (o 'saber fazer') e valores, atitudes (o 'saber ser'), que conduzem a um desempenho profissional eficiente e eficaz em diversos contextos. Rompe-se, assim, com a concepção do trabalhador técnico como 
mero executor de tarefas; quer-se formar, com base no ensino por competências articulado com a preparação no ensino básico, um trabalhador polivalente, que esteja habilitado para responder aos constantes desafios do mundo produtivo, produzindo conhecimentos atualizados, inovadores e criativos.

Segundo Irigoin Barrenne (2004), o currículo por competências foi o modelo escolhido, pois permite uma conceituação, um modo de fazer que combina de forma integrada conhecimentos, habilidades e atitudes necessários para o mercado de trabalho e para o sistema de emprego.

Apesar de a reforma da educação profissional estar construída com base na perspectiva de promover o desenvolvimento de competências necessárias ao exercício de uma profissão, nos diversos níveis escolares, entre eles a EP técnica de nível médio, percebe-se que este modelo curricular vem recebendo diversas críticas, entre elas, as de Ferreti e Silva Júnior (2000). Segundo os autores, a reforma educacional ocorreu em um processo denominado "mercantilização da educação" que se concretiza não pela a lógica da formação de um profissional competente para o trabalho, mas sim pela racionalidade do capital, que busca transferir os direitos sociais do trabalho, de responsabilidade do Estado, para o trabalhador e pela ideologia da empregabilidade ou laboralidade.

Entretanto, apesar de as críticas ao modelo do currículo por competência serem válidas, cabe ressaltar que as novas diretrizes propostas pela LDB e legislações correlatas da EP trouxeram avanços importantes principalmente para EP técnica de nível médio da área da saúde. Isto porque, ao se organizarem as diretrizes curriculares nacionais para o ensino técnico da área da saúde, foi necessário fazer articulações entre as competências profissionais dos trabalhadores da saúde e o conceito ampliado de saúde, que também se encontrava (e ainda se encontra) em pleno processo de reformulação trazido pelo movimento da Reforma Sanitária, que culminou com a institucionalização do Sistema Único de Saúde (SUS), através das leis nos $8.080 / 90$ e $8.142 / 90$.

Nesse sentido, a educação profissional técnica de nível médio na área da enfermagem, conhecida como cursos técnicos em enfermagem, vem sofrendo diversas mudanças pela influência das novas políticas de educação e saúde.

Dentre as principais mudanças, destaca-se a autonomia que os cursos de EP passaram a ter para construir planos de cursos, com características mais flexíveis, interdisciplinares e contextualizadoras, com objetivo de captar novas realidades do processo do trabalho da área da saúde. Além de formar um cidadão com competências profissionais capazes de mantê-lo no mercado de trabalho, bem como torná-lo agente multiplicador do conceito ampliado de saúde, que passou a ser definida como resultante de uma prática 
social cujos fatores condicionantes e determinantes vão além do modelo biomédico de cura da doença.

Sob esta perspectiva, as escolas que formam recursos humanos na área da enfermagem não podem mais ficar alheias aos novos conceitos introduzidos tanto da esfera educativa como da esfera da saúde.

A construção de novos modos de ensinar e aprender na área da saúde passou a ser um dos objetivos das escolas; entretanto, para que isto ocorresse foi necessário reorganizar os currículos vigentes tendo como eixos norteadores a articulação com os serviços de saúde e a incorporação de novas metodologias de ensino capazes de formar profissionais competentes para atender às demandas de saúde da população brasileira.

Portanto, para iniciar o debate sobre a reorganização curricular por competências na área da saúde, torna-se imprescindível compreender as principais mudanças ocorridas no campo da saúde nestas duas últimas décadas.

\section{A formação de recursos humanos em saúde em um contexto de mudanças}

A década de 1980 foi influenciada por reformas em todos os setores da sociedade, sejam eles econômico, político e social, vindo a culminar na promulgação da Constituição da República Federativa do Brasil, em 5 de outubro de 1988. Sem sombra de dúvida a nova Carta Constituinte apresentou alguns avanços para os cidadãos brasileiros, assegurando garantias fundamentais, dentre elas, os descritos em seu artigo 196: "A saúde é direito de todos e dever do Estado, garantido mediante políticas sociais e econômicas que visem à redução do risco de doença e de outros agravos e ao acesso universal e igualitário às ações e serviços para sua promoção, proteção e recuperação" (Brasil, 2006).

A partir deste novo contexto na saúde foi estabelecido, em 1990, o SUS, que teve sua forma definida especialmente pela lei $n^{\circ}$ 8.080/90 (Lei Orgânica da Saúde), que "dispõe sobre as condições para promoção, proteção e recuperação da saúde, a organização e financiamento dos recursos correspondentes" (Brasil, 1990a) e pela lei $\mathrm{n}^{\circ} 8142 / 90$, que “dispõe sobre a participação da comunidade na gestão do SUS e sobre as transferências intergovernamentais de recursos financeiras na área da saúde" (Brasil, 1990b), entre outras.

No mesmo período, em que os conceitos que deram origem ao SUS são propostos, um outro movimento em torno da promoção da saúde surge no Canadá referendado pela promulgação da Carta de Otawa, em que se propõe uma nova concepção de saúde que deveria incluir: paz, educação, moradia, alimentação, renda, ecossistema estável, justiça social e a eqüidade. 
Pasche e Hennington (2006) relatam que o SUS e a promoção da saúde se apresentam, ao mesmo tempo, como movimentos sociais e como práticas teóricas, e que a chegada da promoção da saúde no Brasil coincide com o processo de reformulação do sistema de saúde, cujo desafio se apresentava na direção da reconstrução das práticas e estratégias de intervenção em saúde, identificadas como inadequadas.

Entretanto, as referências explícitas às ações de promoção da saúde foram incorporadas nos dispositivos legais do SUS somente em 1996, na $10^{\text {a }}$ Conferência de Saúde, quando foram discutidos os Modelos de Atenção para Qualidade de Vida e a implementação do Programa de Saúde de Família, ocorrendo a inclusão do tema Promoção da Saúde na agenda da política de saúde.

Diante deste cenário que se anuncia na área da saúde, torna-se necessário que este novo modelo de atenção, constituído por práticas com ênfase nas ações de promoção, prevenção, cura e reabilitação de doenças, de acordo com as necessidades de saúde individuais e coletivas da população (Silva, 2005), seja incorporado no setor saúde, não para sobrepor o modelo hegemônico da saúde, centrado no paradigma biomédico, na hospitalização, na sofisticação tecnológica e no saber clínico, e sim para que concomitante a ele possam ser produzidas novas práticas de saúde.

Devido à necessidade de concretizar estas novas formas de organização da assistência da saúde, é preciso minimizar o distanciamento entre o discurso teórico e a prática, por meio do ordenamento da formação de recursos humanos na área da saúde, conforme descrito no artigo $6^{\circ}, \S 3$, da lei $\mathrm{n}^{\circ}$ 8.080/90.

Pereira (2006) relata que a atribuição da responsabilidade do ordenamento na formação dos trabalhadores da saúde ao Sistema Nacional de Saúde foi um dos grandes avanços da Constituição de 1988 para educação na área da saúde, pois se percebeu que historicamente o setor educacional não respondia às necessidades de profissionalização para o setor saúde em função da pequena oferta de vagas e da inadequação curricular à realidade dos serviços.

Dentre os movimentos de formação de recursos humanos na área da saúde, merece destaque o Programa de Formação em Larga Escala de Pessoal de Nível Médio e Elementar para os Serviços Básicos de Saúde (Projeto Larga Escala), criado no início da década de 1980, cujo objetivo era possibilitar uma formação profissional no serviço com reconhecimento legal. Este programa foi desenvolvido pela área de enfermagem que, incentivada pela falta de sintonia entre o mercado e o setor de formação profissional, além de um contingente de trabalhadores não qualificados, tornou-se pioneira em articular os campos da saúde e educação e do trabalho, por meio de um acordo entre o Ministério da 
Saúde, Ministério da Previdência e Assistência Social e Ministério da Educação, instituído pela portaria de 11 de março de 1980, alterada pela portaria ministerial de 27 de abril de 1984, ratificado pela resolução Ciplan $\mathrm{n}^{\circ} 15$ de $11 / 11 / 85$.

Este projeto, apesar de não ter tido muito sucesso à época, após o movimento da Reforma Sanitária, passou a influenciar outros, como o da Profissionalização dos Trabalhadores da Área de Enfermagem (Profae), que tinha o objetivo de promover a melhoria da qualidade de atenção ambulatorial e hospitalar, a partir da qualificação de 225 mil trabalhadores de enfermagem, que atuavam na área sem qualquer formação acadêmica, em auxiliares de enfermagem em todo território brasileiro.

No processo de formação de recursos humanos de nível médio e elementar, o Profae, criado pelo Ministério da Saúde em 1999, muito contribuiu para a reformulação das propostas curriculares da EP técnica de nível médio na área da enfermagem, pois, ao operacionalizar os cursos promovidos pelo Profae a partir do diagnóstico das condições precárias das escolas e cursos de formação dos profissionais de enfermagem, o Ministério da Saúde teve como desafio formular diretrizes pedagógicas capazes de garantir aos egressos condições mínimas de empregabilidade por meio da certificação do profissional por competências.

Pereira (2006) relata que a noção de competência na EP em saúde foi introduzida por meio do Sistema de Certificação de Competências (SCC) do Profae, descrito como processo de validação das competências adquiridas pelo trabalhador e realizado com base na norma de certificação pactuada entre os atores interessados no processo.

É válido destacar que, quando o Profae foi elaborado, a LDB e as legislações correlatas da EP técnica de nível médio, bem como as políticas públicas da saúde encontravam-se em plena transição. Discutiam-se nesse momento as regulamentações das diretrizes curriculares para a EP e a instituição dos novos modelos assistenciais na área da saúde. Esta situação foi relevante no contexto do ordenamento da formação de recursos humanos para o SUS, pois, para instituir o SCC/Profae, foi necessária a parceria entre o Ministério da Saúde e o Ministério da Educação (Sório, 2002; Pereira, 2006), porque representou uma estratégia de formação factível instituído pelo próprio setor saúde.

\section{O currículo por competência e os pontos de adesão e distanciamento com o campo da educação e saúde}

Conforme já disposto, com a promulgação da lei nº 9.394/96 e correlatas, há um reconhecimento de que a EP tem por objetivo desenvolver competên- 
cias profissionais, para o desempenho eficiente e eficaz de atividades requeridas pela natureza do trabalho.

Com a prerrogativa de reorganizar a EP tendo por base esses novos parâmetros, foi homologada a resolução $\mathrm{CNE} / \mathrm{CEB} \mathrm{n}^{\circ} 4$, de 8 de dezembro de 1999, que instituiu as Diretrizes Curriculares Nacionais para a Educação Profissional de Nível Técnico, atualmente chamadas de Educação Profissional técnica de nível médio, cujo objetivo era definir um conjunto articulado de princípios, critérios e procedimentos a serem observados pelos sistemas de ensino e pelas escolas na organização e no planejamento dos cursos de EP por áreas profissionais, com suas respectivas caracterizações, competências profissionais gerais e cargas horárias mínimas de cada habilitação.

A partir da formulação das diretrizes curriculares, o conceito de 'competência profissional' emerge na EP, sendo definida como a capacidade de articular, mobilizar e colocar em ação valores, conhecimentos e habilidades necessários para o desempenho eficiente e eficaz de atividades requeridas pela natureza do trabalho.

O desenvolvimento de competências profissionais passou a ser a condição sine qua non para a laboralidade, um dos princípios norteadores da EP, entendida como uma forma de manutenção do trabalhador nas atividades produtivas e geradoras de renda em contextos socioeconômicos cambiantes e instáveis e que exige do trabalhador muito mais que repetição de tarefas.

As competências requeridas pela EP, definidas na resolução CNE/CEB n $4 / 99$, são: as básicas, constituídas no ensino fundamental e médio; as profissionais gerais, comuns aos técnicos de cada área; e as profissionais específicas de cada qualificação ou habilitação. Para fins de conclusão de qualificação, habilitação e de especialização, cabe à escola estabelecer perfis profissionais de conclusão que devem ser construídos a partir da aferição simultânea das demandas das pessoas, mercado de trabalho, sociedade e em conformidade com as competências indicadas por esta resolução.

As áreas profissionais, com suas respectivas caracterizações e competências profissionais gerais do profissional da área, também foram descritas com base na resolução CNE/CEB nº 4/99 e nº 5/05 que incluiu 21 áreas profissionais na EP, entre elas a área da saúde.

Ramos (2002a) relata que os perfis de competências, instituídos pelas Diretrizes Curriculares Nacionais da EP, são de natureza mandatória. Portanto, as competências gerais comuns ao técnico definidas pela resolução $\mathrm{CNE} / \mathrm{CEB} \mathrm{n}^{\circ}$ 4/99 deverão ser contempladas na organização curricular de 'todas' instituições que desejam implementar cursos na área da saúde.

Merece destacar que, quando as competências profissionais gerais, comuns aos técnicos da área da saúde foram estabelecidas, foi necessário analisar o processo de trabalho dos profissionais da saúde por meio de 
comissões técnicas compostas por professores e profissionais do setor ou área de produção, uma vez que estes perfis gerais deveriam contemplar a realidade dos profissionais da saúde, com suas características e peculiaridades. Da mesma forma, quando os Referenciais Curriculares Nacionais para Educação Profissional na área da saúde em 2000 foi elaborado, houve a participação das diversas instituições, grupos de profissionais e especialistas da área de saúde, grupo composto por técnicos do Ministério da Saúde e da Organização Pan-americana de Saúde (Opas), profissionais com experiência comprovada em educação de nível médio em cada uma das subáreas da saúde. Na área da Enfermagem, por exemplo, houve a colaboração da Associação Brasileira de Enfermagem (ABEn), que se empenhou em transmitir o pensamento dos educadores, profissionais de serviços e pesquisadores, conforme consubstanciado nos três primeiros seminários nacionais de Diretrizes da Enfermagem (Senaden) e no primeiro Seminário Nacional de Educação Profissional de Nível Técnico em Enfermagem, realizado em Brasília, em julho de 1998.

Outro ponto a ser esclarecido é que, ao fixar as Diretrizes Curriculares Nacionais para EP, o Conselho Nacional de Educação altera uma prática secular da área, a da fixação dos currículos mínimos pelo sistema educacional, responsabilizando e dando autonomia para as instituições de ensino construírem planos de cursos com características flexíveis, interdisciplinares e contextualizadoras, capazes de desenvolver nos seus alunos competências profissionais necessárias para um bom desempenho no mundo de trabalho em constante mutação.

No sentido de desenvolver essas competências profissionais gerais, a escola deve construir um processo educativo permanente para o trabalho e vida social do aluno, sendo necessário primeiramente romper com todo um contexto internalizado pela escola há décadas, o da prática curricular 'conteudista' e descontextualizada com a realidade.

Entretanto, apesar da estrutura curricular baseada em competências criar perspectivas favoráveis à superação de uma pedagogia centrada na transmissão de conteúdos, deve-se levar em conta que este enfoque, se não for devidamente apropriado, poderá levar à criação de novos códigos que aproximam a educação das tendências produtivas associadas ao mercado de trabalho, bem como à valorização das potencialidades individuais do trabalhador, responsabilizando-o por seu desempenho no emprego - fato que resultaria na volta a um tecnicismo já suficientemente condenado por não assegurar uma formação abrangente (Ramos, 2002b).

Portanto, implementar um currículo por competências torna-se um processo desafiador para escola e sua comunidade escolar, pois, para construir um currículo capaz de desenvolver as competências para o mundo do trabalho, deve haver um esforço conjunto envolvendo a escola (que neces- 
sita estar articulada ao mundo do trabalho), e o aluno deve ser incentivado, pois ambos devem participar ativamente deste processo.

\section{A reorganização curricular dos cursos de educação profissional técnica de nível médio em enfermagem no estado do Rio de Janeiro}

No bojo desta mudança no âmbito da educação profissional, a estrutura curricular do curso técnico de enfermagem, por conseqüência, sofre reformulação. Conforme é instituído na resolução CNE/CEB n 04/99, a organização dos currículos da EP deve estar em sintonia com os princípios gerais, tais como: a articulação da educação profissional técnica com o ensino médio e o respeito aos valores estéticos, políticos e éticos; e com os princípios específicos, tais como: competências para a laborabilidade; flexibilidade, interdisciplinaridade e contextualização; identidade dos perfis profissionais; atualização permanente dos cursos e currículos e autonomia da escola.

Embora, todos os princípios tenham influência direta na construção dos currículos de $\mathrm{EP}$, daremos destaque neste texto ao princípio da flexibilidade, por constituir temática desafiadora para os cursos de EP, que vêm há décadas reproduzindo currículos por disciplina, centralizadores e descontextualizados.

O termo flexibilidade, conforme definido no parecer CNE/CEB n ${ }^{\circ} 16 / 99$, reflete a construção dos currículos em diferentes perspectivas: na oferta dos cursos, na organização de conteúdos por disciplinas, etapas ou módulos, em atividades nucleadoras, projetos, metodologias e gestão dos currículos. Está também diretamente ligado ao grau de autonomia das instituições de EP e ao projeto político-pedagógico elaborado, executado e avaliado com a efetiva participação de todos os agentes educacionais, em especial os docentes.

Na perspectiva do princípio da flexibilidade, cabe às escolas, em especial às da área da saúde, estruturar seus planos de curso vinculados à realidade do mundo do trabalho, com base no acompanhamento das demandas do mercado e da sociedade e comprometidas com o contexto de saúde vigente, com o objetivo de alcançar um adequado perfil profissional de conclusão.

Antes da LDB n ${ }^{\circ}$ 9.394/96 e CNE/CEB nº 04/99, os cursos técnicos eram regidos pela lei $n^{\circ} 5.692 / 71$, e pelo parecer $n^{\circ} 45 / 72$, que fixou as diretrizes e bases para o ensino de $1^{\circ}$ e $2^{\circ}$ graus e definiu os mínimos a serem exigidos em cada habilitação profissional ou conjunto de habilitações afins do ensino do $2^{\circ}$ grau, inclusive para os cursos de técnico e de auxiliar de enfermagem, respectivamente.

Com base nessas legislações, os cursos técnicos passaram a ter currícu- 
los mínimos padronizados, com matérias obrigatórias, desdobradas e tratadas como disciplinas, ou seja, uma estrutura curricular nada flexível.

A exemplo da enfermagem, seus cursos foram organizados com base no currículo mínimo instituído pelo artigo $5^{\circ}$ da resolução $\mathrm{n}^{\circ} 7 / 77$, que definiu e distribuiu as matérias da parte de formação especial, para a habilitação em técnico de enfermagem, em um mínimo de matérias profissionalizantes (Introdução à Enfermagem, Noções de Administração de Unidades de Enfermagem, Enfermagem Médica, Enfermagem Cirúrgica, Enfermagem Materno-Infantil, Enfermagem Neuropsiquiátrica, Enfermagem em Saúde Pública, Psicologia Aplicada e Ética Profissional) e disciplinas instrumentais (Higiene e Profilaxia, Estudos Regionais, Anatomia e Fisiologia Humanas, Microbiologia e Parasitologia, Nutrição e Dietética), cujo estudo constitui pré-requisito para as matérias profissionalizantes.

Como podemos observar, a incorporação do currículo mínimo com enfoque no modelo biomédico, centrado no espaço hospitalar, na especialização e uso de tecnologias permaneceu presente no curso técnico de enfermagem durante vinte anos, somente sendo desestimulado com a LDB, em 1996, que revoga o antigo dispositivo legal.

A orientação de centralização (parecer $\mathrm{n}^{\circ}$ 45/72) dos currículos mínimos passa, então, a ser de descentralização (parecer CNE/CEB n ${ }^{\circ}$ 16/99 e resolução $\mathrm{CNE} / \mathrm{CEB} \mathrm{n}^{\circ}$ 04/99), outorgando à escola autonomia em organizar e reorganizar seus currículos, de forma flexível, interdisciplinar, contextualizada com enfoque nas competências profissionais para cada perfil de conclusão pretendido, em função das demandas sociais, do mercado, das peculiaridades locais e regionais e da capacidade institucional.

Sabemos que tais mudanças não são fáceis e dependem de muita articulação do corpo técnico-administrativo da escola, do coordenador de curso e do corpo docente com as novas legislações e contextos sociopolítico e socioeconômico do país. Na área da saúde, é importante ressaltar que os conceitos e modelos assistenciais também mudaram neste espaço de tempo e, por conseqüência, devem ser discutidos e inseridos no processo de reorganização curricular.

Pinheiro et al. (2003) afirmam que os currículos das escolas de saúde devem possibilitar a construção de práticas sanitárias de orientação holística e com comprometimento social que incorporem conceitos da integralidade e humanização da assistência, bem como precisam ser estruturados de forma a permitir que o aluno seja capaz de 'aprender a aprender' em um mundo de trabalho com crescente incorporação de tecnologias e com uma demanda variada de serviços de saúde oriundas das diferentes necessidades da população.

Outro aspecto a ser contemplado na reorganização curricular, segundo Pinheiro et al. (2003), é a revisão do conteúdo curricular centrado nas ciên- 
cias biológicas, que não tem conseguido dar conta da integralidade do ser humano (ser biopsicossocial) e dos fatores determinantes que atuam sobre sua saúde (alimentação, moradia, saneamento básico, meio ambiente, trabalho, renda, educação, transporte, lazer e acesso aos bens e serviços essenciais). Portanto, conteúdos além da anatomia e microbiologia, como sociologia, antropologia, políticas públicas e sociais, economia, planejamento, comunicação e outros, necessitam ser incorporados aos currículos atuais da área da saúde.

Diante deste cenário de tantas mudanças na formação profissional, permanecem, então, alguns importantes questionamentos: Como será que as escolas estão se adaptando à LDB, visto que ela já está há dez anos em vigor? Os currículos escolares estão sendo reestruturados com a nova orientação ou apenas adaptados ao novo modelo? Estão os dirigentes e coordenadores de cursos sintonizados com as novas legislações? Como os órgãos gestores da educação estão reagindo para adequar tal realidade?

Sabemos que as respostas a tais perguntas merecem uma análise minuciosa dos projetos políticos pedagógicos das escolas nesta última década, o que não é objetivo deste artigo. O que queremos é apenas descrever as principais mudanças ocorridas neste período e refletir sobre a necessidade da reorganização curricular dos cursos técnicos de enfermagem, sob a perspectiva de formar profissionais com habilidades e competências para atuar de forma consciente e reflexiva em face da realidade dos serviços e das necessidades e prioridades da saúde da população.

Neste sentido, construir e planejar uma proposta educacional comprometida com a formação e o desenvolvimento de cidadãos e profissionais competentes deve ser o ideal de toda escola, mesmo que esses objetivos pareçam uma utopia. Como educadores não podemos ficar imobilizados por acharmos que será impossível que mudanças ocorram no sistema educacional ou que um trabalho educacional eficiente não poderá ser levado a cabo devido às precárias condições e recursos.

A formação de grupos de trabalho para discutir e reorganizar a prática curricular deve ser estimulada. É necessário que os órgãos gestores dos vários sistemas de ensino da União, distrito federal, estado e município, bem como os órgãos de fiscalização profissional fiquem atentos às regulamentações da EP.

No Rio de Janeiro, um dispositivo legal utilizado pela Secretaria de Educação foi a deliberação $n^{\circ} 295 / 2005$, que estabeleceu as normas para o credenciamento de instituições e a autorização de cursos de Educação Profissional técnica de nível médio para o sistema estadual de ensino do Rio de Janeiro. A partir desta deliberação, ficou instituído que as escolas públicas ou privadas interessadas em ofertar cursos de EP técnica de nível médio deverão requerer ao Conselho Estadual de Educação o credenciamento da 
instituição, observando alguns itens, como proposta pedagógica e plano de curso.

O plano de curso, de acordo com esta deliberação, deverá ser detalhado, segundo o modelo estrutural dos referenciais curriculares nacionais da EP de técnica de nível médio na área da saúde, conforme é destacado a seguir:

I - apresentação, com justificativa, objetivos, requisitos de acesso e perfil profissional de conclusão de curso, área profissional à qual pertence e regime de funcionamento;

II - estrutura curricular contendo:

a) funções: as categorias que privilegiam as atividades principais do técnico;

b) subfunções: compreendidas como detalhamento de uma função e que irão contribuir para definição de competências e habilidades;

c) competências: categoria que está articulada ao processo de aquisição do conhecimento, abrangendo operações mentais básicas até as mais complexas, necessárias ao exercício de determinada função - 'o saber';

d) habilidades: categoria referida mais diretamente à aplicação prática de uma competência adquirida - 'saber fazer';

e) bases tecnológicas: componentes essenciais para que o aluno venha a dominar as competências e habilidades necessárias ao exercício da profissão;

f) bases científicas e instrumentais: componentes essenciais para que haja a compreensão das bases tecnológicas;

g) plano de estágio;

h) matriz curricular;

IV - plano de estágio profissional supervisionado, atividades práticas e atividades extracurriculares;

$\mathrm{V}$ - termos de convênios firmados com empresas e outras instituições que sejam vinculadas ao curso;

VI - plano de capacitação permanente e continuada para docentes que atuam no curso.

Esta deliberação acrescenta, também, que a prática profissional, elemento fundamental do currículo da EP técnica, deve ser incluída na carga horária mínima de cada habilitação e deverá ser orientada e acompanhada por profissional qualificado e habilitado. Sua relevância deve-se à garantia do estabelecimento das diretrizes já instituídas pela LDB e correlatas para EP, pois se a instituição de ensino não estiver dentro das normas preestabelecidas corre o risco de perda do credenciamento.

Formar profissionais competentes numa área em plena transformação, como a da saúde, exige esforço conjunto dos órgãos gestores, dos serviços, das instituições de ensino, ou seja, de todos os envolvidos na formação dos 
recursos humanos para a área. Entretanto, para que a articulação entre educação, saúde e serviços aconteça, é necessário formular, implantar e implementar dispositivos facilitadores e comprometidos com a formação, qualificação e requalificação profissional, e também com a reformulação das práticas de saúde sintonizadas com as políticas de educação e saúde vigentes.

\section{Considerações finais}

A EP técnica de nível médio da saúde, em especial da enfermagem, vem construindo ao longo destes dez anos de LDB um novo discurso, o de formar profissionais para um mundo de trabalho que almeja, não mais mera mão-de-obra, e sim profissionais autônomos, críticos e competentes para atuar na área da saúde que se encontra em transformação, tanto no que se refere ao aparato tecnológico como à concepção de atenção à saúde voltada aos princípios do SUS. A responsabilidade de formar profissionais com estas características, por si só, é fonte inspiradora para a reformulação dos currículos educacionais para o setor saúde.

É preciso analisar e reorganizar as práticas de enfermagem, construir e reconstruir novos planos de curso em busca da formação de um profissional que tenha as competências básicas para se manter no mundo e no trabalho, bem como de um novo olhar sobre a prática de saúde, com base no princípio da integralidade e humanização da assistência e no compromisso com a promoção da saúde em todos os níveis de atenção.

Por intermédio da educação podemos transformar, e é a partir de uma nova estrutura curricular escolar, que vislumbre a formação de profissionais de enfermagem competentes para o desempenho de sua prática profissional, que podemos acreditar em mudanças no setor saúde.

Portanto, encontra-se em nossas mãos, escola, comunidade e corpo docente, a formação dos novos trabalhadores da área da saúde com competência profissional necessária para transformar a realidade do sistema de saúde vigente. 


\section{Notas}

1 Professora do Curso Técnico de Enfermagem da Escola Técnica Estadual de Saúde Herbert Daniel de Souza, da Fundação de Apoio à Escola Técnica do Estado do Rio de Janeiro (Faetec), e analista de gestão em saúde do Instituto de Pesquisa Clínica Evandro Chagas, da Fundação Oswaldo Cruz (Ipec/Fiocruz), Rio de Janeiro, Brasil. Mestre em Enfermagem pela Universidade Federal do Estado do Rio de Janeiro (Unirio). <suze.santanna@ipec.fiocruz.br>

Correspondência: Fundação de Apoio à Escola Técnica do Estado do Rio de Janeiro, Escola Técnica Estadual de Saúde Herbert Daniel de Souza, Rua Clarimundo de Melo, 847, Quintino Bocaiúva, Rio de Janeiro, Brasil, CEP 21311-280.

2 Diretora da Escola Técnica Estadual de Saúde Herbert Daniel de Souza, da Fundação de Apoio à Escola Técnica do Estado do Rio de Janeiro (Faetec), Rio de Janeiro, Brasil. Mestre em Enfermagem pela Universidade Federal do Rio de Janeiro (UFRJ). $<$ lennes@ig.com.br>

3 Coordenadora do Curso Técnico de Enfermagem da Escola Técnica Estadual de Saúde Herbert Daniel de Souza, da Fundação de Apoio à Escola Técnica do Estado do Rio de Janeiro (Faetec), Rio de Janeiro, Brasil. Mestre em Ensino de Ciências da Saúde e do Meio Ambiente pelo Centro Universitário Plínio Leite (Unipli). <luiza.hss@terra.com.br>

4 Diretora adjunta da Escola Técnica Estadual de Saúde Herbert Daniel de Souza, da Fundação de Apoio à Escola Técnica do Estado do Rio de Janeiro (Faetec), Rio de Janeiro, Brasil. Especialista em Promoção da Saúde pela Universidade Federal Fluminense (UFF). <sanreoli@uol.com.br>

5 Professor assistente do Departamento de Direito Comercial e do Trabalho da Faculdade de Direito da Universidade do Estado do Rio de Janeiro (Uerj). Mestre em Direito pela Universidade Gama Filho (UGF). <leosantanna@uerj.br>

\section{Referências}

BRASIL. Lei no 8080, de 19 de setembro de 1990a. Dispõe sobre as condições para a promoção, proteção e recuperação da saúde, a organização e o funcionamento dos serviços correspondentes e dá outras providências. Diário Oficial da União, Brasilia, DF, 20 set. 1990.

Lei $\mathrm{n}^{\circ} 8142$, de 29 de dezembro de 1990b. Dispõe sobre a participação da comunidade na gestão do Sistema Único de Saúde (SUS) e sobre as transferências intergovernamentais de recursos financeiros na área da saúde e dá outras providências. Diário Oficial da União, Brasília, DF, 31 dez. 1990.

Lei $\mathrm{n}^{\circ}$ 9.394, de 20 de dezembro de 1996. Estabelece as Diretrizes e Bases da Educação Nacional. Diário Oficial da União, Brasília, DF, 23 dez. 1996.

Decreto $\mathrm{n}^{\circ} 2.208$, de 17 de abril de 1997. Regulamenta o parágrafo $2^{\circ}$ do art. 36 e os arts. 39 a 42 da lei $n^{\circ} 9.394$, de 20 de dezembro de 1996, que estabelece as dire- 
trizes e bases da educação nacional. Diário Oficial da União, Brasília, DF, 18 abr. 1997.

Conselho Nacional de Educação (CNE). Resolução $\mathrm{n}^{\circ} 4$, de 8 de dezembro de 1999. Institui as Diretrizes Curriculares Nacionais para a Educação Profissional de Nível Técnico. Diário Oficial da União, Brasília, DF, 7 out. 1999. Seção 1, p. 52.

Conselho Nacional de Educação (CNE). Parecer $\mathrm{n}^{\circ} 16$, de 5 de outubro de 1999. Diretrizes Curriculares Nacionais para a Educação Profissional de Nível Técnico. Disponível em: <www.mec.gov.br/cne/ parecer.shtm>. Acesso em: 7 ago. 2005.

. Ministério da Educação. Educação profissional: Referenciais Curriculares Nacionais da Educação Profissional de Ensino Técnico - área Saúde. Brasília: MEC, 2000.

. Decreto $\mathrm{n}^{\circ} 5.154$, de 23 de julho de 2004. Regulamenta o $\S 2^{\circ}$ do artigo 36 e os arts. 39 a 41 da lei $\mathrm{n}^{\circ}$ 9.394, de 20 de dezembro de 1996, que estabelece as diretrizes e bases da educação nacional, e dá outras providências. Diário Oficial da União, Brasília, DF, 24 jul. 2004.

Conselho Nacional de Educação. Parecer $\mathrm{n}^{\circ}$ 39, de 8 de dezembro de 2004. Aplicação do decreto $\mathrm{n}^{\circ} 5.154 / 2004$ na Educação Profissional Técnica de Nível Médio e no Ensino Médio. Disponível em: $<$ www.mec.gov/setec $>$. Acesso em: 7 ago. 2005

Conselho Nacional de Educação. Resolução $n^{\circ} 1$, de 3 de março de 2005. Atualiza as Diretrizes Curriculares Nacionais definidas pelo Conselho Nacional de Educação para o Ensino Médio e para a Educação Profissional Técnica de nível médio às disposições do Decreto n ${ }^{\circ}$ 5.154/2004. Diário Oficial da República Federativa do Brasil, Brasília, DF, 11 mar. 2005.

Constituição da República Federativa do Brasil (1988). Atualizada até 2 jan.
2006. 11.ed. rev., atual. e ampl. São Paulo: Revista dos Tribunais, 2006.

Ministério da Saúde. Secretaria de Vigilância em Saúde. Política Nacional de Promoção da Saúde. Brasília: Ministério da Saúde, 2006. (Série B. Textos Básicos de Saúde).

CONSELHO ESTADUAL DE EDUCAÇÃO. Deliberação CEE no 295/2005. Estabelece normas para o credenciamento de instituições e autorização de cursos de Educação Profissional Técnica de Nível Médio para o Sistema Estadual de Ensino do Rio de Janeiro. Diário Oficial da República, Brasília, DF, de 26 de abril de 2006.

FERRETTI, Celso João; SILVA JUNIOR, João dos Reis. Educação profissional numa sociedade sem empregos. Cadernos de Pesquisa, São Paulo, n. 109, p. 43-66, 2000.

FRIGOTTO, Gaudêncio. et al. A política de educação profissional no Governo Lula: um percurso histórico controvertido. Educação \& Sociedade, Campinas, v. 26, n. 92, p. 1087-1113, 2005. Disponível em: $<$ www.scielo.br/scielo.php?script=sci_art text\&pid=S0101-73302005000300017>.

Acesso em: 5 maio 2007.

IRIGON BARRENNE, Maria Etiennette et al. Competência profissional: manual de conceitos, métodos e aplicações no setor saúde. Rio de Janeiro: Senac Nacional, 2004.

MOREIRA, Almerinda; OGUISSO, Taka. Profissionalização da enfermagem brasileira. Rio de Janeiro: Guanabara Koogan, 2005.

PASCHE, Dário Frederico; HENNINGTON, Élida Azevedo. Promoção da saúde e o Sistema Único de Saúde. In: CASTRO, Adriana; MALO, Miguel (Orgs.). SUS ressignificando a promoção da saúde. São Paulo: HucitecOpas, 2006. p. 19-40.

PAIM, Jarnilson Silva. Vigilância da Saúde: tendências de reorientação de modelos assistenciais para promoção da saúde. In: 
CZERINA, Dina. et al. Promoção da saúde: conceitos, reflexões, tendências. Rio de Janeiro: Fiocruz, 2003. p. 161-174.

PEREIRA, Isabel Brasil. Políticas de saúde e formação do trabalhador. In: ESCOLA POLITÉCNICA DE SAÚDE JOAQUIM VENÂNCIO (Org.). Textos de apoio em politicas de saúde. Rio de Janeiro: Editora Fiocruz, 2005. p. 117-142. Série Trabalho e Formação em Saúde.

PEREIRA, Isabel Brasil; RAMOS, Marise Nogueira. Educação profissional em saúde. Rio de Janeiro: Editora Fiocruz, 2006.

PINHEIRO, Eliana de Fátima Catussi et al. Profissional de saúde: a inter-relação entre formação e prática. Revista Formação, n. 8, p. $45-55,2003$.

RAMOS, Marise Nogueira. Indicações teórico-metodológicas para a elaboração de currículos na educação profissional de nível técnico em saúde. In: CASTRO, Janete Lima de (Org.). Profae: educação profissional em saúde e cidadania. Brasília: Ministério da Saúde, 2002. p. 55-86.

2002b A educação profissional pela pedagogia das competências e a superfície dos documentos oficiais. Educação \& Sociedade, Campinas, v. 23, n. 80, p. 401-422.

SILVA, José Paulo Vicente da et al. Sistema Único de Saúde: reafirmando seus princípios e diretrizes para fazer avançar a Reforma Sanitária Brasileira. In: ESCOLA POLITÉCNICA DE SAÚDE JOAQUIM VENÂNCIO (Org.). Textos de apoio em politicas de saúde. Rio de Janeiro: Editora Fiocruz, 2005. p. 43-73.

SÓRIO, Rita Elizabeth da Rocha. Inovações no Campo da Gestão de Projetos Sociais: uma reflexão à luz da experiência do Profae. In: CASTRO, Janete Lima de (Org.). Profae: educação profissional em saúde e cidadania. Brasília: Ministério da Saúde, 2002. p. 17-29.

Recebido em 28/06/2007

Aprovado em 14/10/2007 
